\title{
On the quality of the Nimbus 7 LIMS Version 6 water vapor profiles and distributions
}

\author{
E. E. Remsberg ${ }^{1}$, M. Natarajan ${ }^{1}$, G. S. Lingenfelser ${ }^{2}$, R. E. Thompson ${ }^{3}$, B. T. Marshall ${ }^{3}$, and L. L. Gordley ${ }^{3}$ \\ ${ }^{1}$ NASA Langley Research Center, 21 Langley Blvd., Mail Stop 401B, Hampton, VA 23681, USA \\ ${ }^{2}$ SSAI, 1 Enterprise Parkway, Hampton, VA 23661, USA \\ ${ }^{3}$ GATS, Inc. 11864 Canon Blvd., Suite 101, Newport News, VA 23606, USA
}

Received: 22 June 2009 - Published in Atmos. Chem. Phys. Discuss.: 1 September 2009

Revised: 25 November 2009 - Accepted: 26 November 2009 - Published: 7 December 2009

\begin{abstract}
This report describes the quality of the Nimbus 7 Limb Infrared Monitor of the Stratosphere (LIMS) water vapor $\left(\mathrm{H}_{2} \mathrm{O}\right)$ profiles of $1978 / 79$ that were processed with a Version 6 (V6) algorithm and archived in 2002. The V6 profiles incorporate a better knowledge of the instrument attitude for the LIMS measurements along its orbits, leading to improvements for its temperature profiles and for the registration of its water vapor radiances with pressure. As a result, the LIMS V6 zonal-mean distributions of $\mathrm{H}_{2} \mathrm{O}$ exhibit better hemispheric symmetry than was the case from the original Version 5 (V5) dataset that was archived in 1982. Estimates of the precision and accuracy of the $\mathrm{V}^{6} \mathrm{H}_{2} \mathrm{O}$ profiles are developed and provided. Individual profiles have a precision of order 5\% and an estimated accuracy of about $19 \%$ at $3 \mathrm{hPa}$, $14 \%$ at $10 \mathrm{hPa}$, and $26 \%$ at $50 \mathrm{hPa}$. Profile segments within about $2 \mathrm{~km}$ of the tropopause are often affected by emissions from clouds that appear in the finite field-of-view of the detector for the LIMS $\mathrm{H}_{2} \mathrm{O}$ channel. Zonally-averaged distributions of the LIMS V6 $\mathrm{H}_{2} \mathrm{O}$ are compared with those from the more recent Microwave Limb Sounder (MLS) satellite experiment for November, February, and May of 2004/05. The patterns and values of their respective distributions are similar in many respects. Effects of a strengthened BrewerDobson circulation are indicated in the MLS distributions of the recent decade versus those of LIMS from 1978/79. A tropical tape recorder signal is present in the 7-month time series of LIMS V6 $\mathrm{H}_{2} \mathrm{O}$ with lowest values in February 1979, and the estimated, annually-averaged "entry-level" $\mathrm{H}_{2} \mathrm{O}$ is 3.5 to 3.8 ppmv. It is judged that this historic LIMS water
\end{abstract}

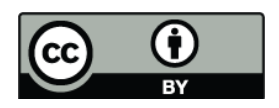

Correspondence to: E. E. Remsberg (ellis.e.remsberg@nasa.gov) vapor dataset is of good quality for studies of the near globalscale chemistry and transport for pressure levels from $3 \mathrm{hPa}$ to about 70 to $100 \mathrm{hPa}$.

\section{Background}

The Nimbus 7 Limb Infrared Monitor of the Stratosphere (LIMS) experiment operated successfully from 25 October 1978 through 28 May 1979, the planned lifetime of the onboard cryogen gases used to cool its detectors (Gille and Russell, 1984). LIMS provided daily, near-global distributions of stratospheric $\mathrm{H}_{2} \mathrm{O}$. The LIMS Version 5 (V5) Level 2 profiles and Level 3 zonal Fourier coefficients were archived in 1982 and 1983, respectively, and they have been used for numerous scientific studies. The present report describes the quality of the updated, Version 6 (V6) $\mathrm{H}_{2} \mathrm{O}$ dataset, archived in 2002.

As a review, it is noted that the original, LIMS V5 $\mathrm{H}_{2} \mathrm{O}$ distributions were used to examine issues related to stratospheric chemistry (e.g., LeTexier et al., 1988; Garcia and Solomon, 1994) and transport (e.g., Gray and Pyle, 1986; Butchart and Remsberg, 1986; and Gille et al., 1987). Its $\mathrm{H}_{2} \mathrm{O}$ distributions were also used in studies of the stratospheric budget of water vapor, and, in particular, to estimate the $\mathrm{H}_{2} \mathrm{O}$ mixing ratio (or $\left[\mathrm{H}_{2} \mathrm{O}\right]_{e}$ ) as it enters the tropical stratosphere from below (Jones et al., 1986; Hansen and Robinson, 1989). Jones et al. (1986) defined that quantity as $\left[\mathrm{H}_{2} \mathrm{O}\right]_{e}=\mathrm{H}_{2} \mathrm{O}-2 \times\left(\left[\mathrm{CH}_{4}\right]_{e}-\mathrm{CH}_{4}\right)$, where the values of $\mathrm{H}_{2} \mathrm{O}$ and $\mathrm{CH}_{4}$ are for the same pressure level and $\left[\mathrm{CH}_{4}\right]_{e}$ is their value of the entry level for methane (about $1.6 \mathrm{ppmv}$ in 1979). Their estimated, annually-averaged, values of $\left[\mathrm{H}_{2} \mathrm{O}\right]_{e}$ ranged from 2.7 ppmv to 3.3 ppmv.

Published by Copernicus Publications on behalf of the European Geosciences Union. 
Russell (1987) and Remsberg et al. (1990) provided the monthly distributions of stratospheric $\mathrm{H}_{2} \mathrm{O}$ from the LIMS V5 Level 3 (mapped) dataset. Later, Chiou et al. (1993, 1996) compared the LIMS V5 distributions with those from the Stratospheric Aerosol and Gas Experiment (SAGE II) of the Earth Radiation Budget Satellite (ERBS) and from the Stratospheric and Mesospheric Sounder (SAMS) instrument of Nimbus 7. They found general agreement among those three data sets, at least within their combined error bars. However, the $\mathrm{H}_{2} \mathrm{O}$ values from all three experiments were subject to rather large errors, particularly in the lower stratosphere. Their respective meridional gradients of $\mathrm{H}_{2} \mathrm{O}$ also differed somewhat with each other and with those obtained from subsequent ER-2 aircraft measurement campaigns.

The precisions and accuracies for the LIMS V5 $\mathrm{H}_{2} \mathrm{O}$ profiles were reported in Russell et al. (1984), Remsberg et al. (1984a), and Remsberg and Russell (1987). Their combined errors are no greater than $17 \%$ in the middle stratosphere ( 3 to $30 \mathrm{hPa}$ ), due primarily to the effects of profile registration and temperature biases for their retrievals. Their quality is not as good near the stratopause because that is where the radiances approach the detector noise for the $\mathrm{H}_{2} \mathrm{O}$ channel. In the upper stratosphere the radiances originate from strong water vapor lines in the LIMS broadband $\mathrm{H}_{2} \mathrm{O}$ channel from 6.4 to $7.3 \mu \mathrm{m}$. Those lines are nearly saturated and lead to a highly non-linear relation between radiance and retrieved $\mathrm{H}_{2} \mathrm{O}$ concentration. Kerridge and Remsberg (1989) reported on the effects of an additional complication for the retrieval of upper stratospheric LIMS $\mathrm{H}_{2} \mathrm{O}$, particularly during daylight. They showed that retrieved $\mathrm{H}_{2} \mathrm{O}$ values at those altitudes were larger for day than for night-a consequence of not accounting for non-local thermodynamic equilibrium (non-LTE) emissions in the daytime $\mathrm{H}_{2} \mathrm{O}$ radiances. That additional, non-LTE emission is most significant in the mesosphere, but its residual effects also extend to the retrieved stratospheric profiles of LIMS (Mertens et al., 2002).

The LIMS V5 $\mathrm{H}_{2} \mathrm{O}$ is also not as accurate in the upper troposphere/lower stratosphere (UT/LS) (Kley et al., 2000). In particular, there are systematic $\mathrm{H}_{2} \mathrm{O}$ errors just above the tropical tropopause due to the LIMS V5 temperatures being a bit too warm, to the uncertainties for the interfering effects of the pressure-induced $\mathrm{O}_{2}$ continuum emission, and to the contaminating emissions from aerosols and clouds that were not accounted for. Furthermore, in the tropics there is a sharp increase of $\mathrm{H}_{2} \mathrm{O}$ and temperature just below the tropopause. The instantaneous, finite vertical field-of-view (FOV) width of the LIMS $\mathrm{H}_{2} \mathrm{O}$ channel is $3.6 \mathrm{~km}$ at its $50 \%$ response points, so it averages across the region of the tropopause. Although the deconvolution procedure accounts for the effects of any FOV side lobes in the radiances prior to their retrieval, the spatial smoothing effect of the main FOV lobe is still present.

Section 2 of this report describes the important changes of the LIMS V6 water vapor algorithm and the improvements for its profiles and distributions. Its zonally-averaged, night- time distribution for mid November is compared qualitatively with the Earth Observing System (EOS Aura) Microwave Limb Sounder (MLS) Version 2.2 (v2.2) $\mathrm{H}_{2} \mathrm{O}$ of 2004. Both cross sections exhibit many of the same features. Section 3 gives estimates of the precision and systematic errors for single LIMS $\mathrm{V}_{6} \mathrm{H}_{2} \mathrm{O}$ profiles. Section 4 contains qualitative comparisons between LIMS and MLS for February and May. Although their overall distributions are similar, they show significant differences near the tropical hygropause and in the upper stratosphere at high latitudes. Section 5 contains a brief discussion of some initial scientific findings from the LIMS distributions, and Sect. 6 summarizes the quality of the V6 $\mathrm{H}_{2} \mathrm{O}$ dataset.

\section{LIMS V6 water vapor}

\subsection{LIMS V6 algorithm for $\mathrm{H}_{2} \mathrm{O}$}

A major reason for the update of the overall LIMS algorithm to V6 is the incorporation of more recent spectroscopic line parameters for the retrievals of the LIMS profiles of temperature and each of its species (ozone, water vapor, nitric acid, and nitrogen dioxide), so that they are more compatible with the corresponding profile quantities obtained with the follow-on sensor systems of the Upper Atmosphere Research Satellite (UARS), of EOS Aura, and of the Environmental Satellite (ENVISAT) of the European Space Agency. The V6 forward model for the $\mathrm{H}_{2} \mathrm{O}$ and $\mathrm{CH}_{4}$ radiances in the LIMS channel makes use of HITRAN 1996 line parameters (Rothman et al., 1998), although the parameters for the $v_{2}$ lines of $\mathrm{H}_{2} \mathrm{O}$ from 6.4 to $7.3 \mu \mathrm{m}$ are nearly unchanged from the ones used for the retrieval of the earlier V5 profiles. The more recent improvements in the widths and positions of the $\mathrm{H}_{2} \mathrm{O}$ lines in later editions of HITRAN have little to no effect for the forward radiances of the LIMS broad-band measurements at 6 to 7 micrometers. Effects of overlap for the lines of $\mathrm{H}_{2} \mathrm{O}$ and $\mathrm{CH}_{4}$ are accounted for with an additional, band model emissivity table. The effects of the underlying, interfering radiance from the $\mathrm{O}_{2}$ continuum are updated based on the empirical model of Thibault et al. (1997), and the temperature dependence of that model is significantly different from what was used for $\mathrm{O}_{2}$ in V5, particularly for the colder temperatures of the lower stratosphere. This change is one reason that the retrieved $\mathrm{V}_{6} \mathrm{H}_{2} \mathrm{O}$ profiles of the tropical lower stratosphere are not quite as dry as those of V5.

The Nimbus 7 spacecraft was in a Sun-synchronous orbit, and the LIMS radiometer viewed the atmospheric limb and in a direction 146.5 degrees clockwise from the spacecraft velocity vector (Gille and Russell, 1984). Figure 1 is a schematic of the effective view of the LIMS measurement array (or the instantaneous FOVs for the LIMS channels) at the horizon for a down/up scan pair, traveling from right to left along the orbit. A scan begins with the center of the array at $153 \mathrm{~km}$, moving downward to $38 \mathrm{~km}$ below the solid 


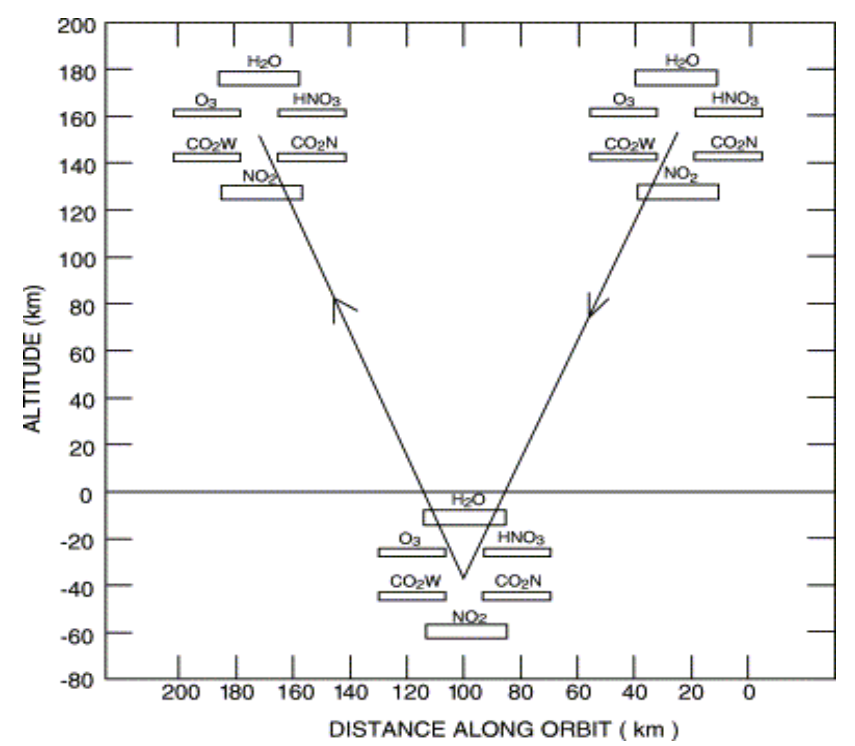

Fig. 1. Locations and relative sizes of the LIMS channel fieldsof-view (FOV) projected to the limb at the tops and bottom of a down/up scan pair.

Earth limb, and then returning upward again. The complete down/up sequence occurs in $24 \mathrm{~s}$, while its limb position travels $144 \mathrm{~km}$ along the orbit. The angular resolution for the $\mathrm{H}_{2} \mathrm{O}$ detector is 1 milliradian, and it subtends a vertical width of $3.6 \mathrm{~km}$ for the tangent layer at the horizon. Effectively, it is the geometry of the limb measurement that determines the vertical resolution of its retrieved profiles.

Accuracies for the LIMS $\mathrm{H}_{2} \mathrm{O}$ profiles are dominated by the effects of instrument jitter on the radiances and the uncertainties in the atmospheric temperature-pressure profiles (or $T(p)$ ) and the associated registration of the $\mathrm{H}_{2} \mathrm{O}$ radiances with pressure-altitude (Russell et al., 1984). The point spacing for the measured Level 2 profile data is $0.375 \mathrm{~km}$ and all the radiance samples were used. In addition, the adjacent down/up scan pairs were retrieved using an interleave procedure and the results averaged. These steps reduced much of the effects of jitter in the radiances and yielded an effective vertical resolution of $3.7 \mathrm{~km}$ for $\mathrm{H}_{2} \mathrm{O}$. The better determination of spacecraft/instrument orbital attitude for LIMS V6 has also led to more accurate temperature profiles (Remsberg et al., 2004). Although $T(p)$ was retrieved at about $\sim 2 \mathrm{~km}$ vertical resolution, the effects of any vertical temperature structure were minimized in the retrieved $\mathrm{H}_{2} \mathrm{O}$ profiles, at least to first order. A Gaussian smoother with a nearly $1.5 \mathrm{~km}$ vertical halfwidth at half maximum was employed for the final retrieval of the $\mathrm{H}_{2} \mathrm{O}$ profiles. The altitude range of good profile data was set by a noise variance criterion. The V6 profiles were also output at the more frequent spacing of about 1.6 degrees of latitude along an orbit, rather than the nearly 4 degree separation for the V5 dataset. As a result, the V6 $\mathrm{H}_{2} \mathrm{O}$ profiles and distributions have a quality and stability that is improved over that from the original V5 algorithm.
First-order corrections for the interfering effects of $\mathrm{CH}_{4}$ were achieved using the seasonal, zonal mean cross sections of 1994 from the UARS Halogen Occultation Experiment (HALOE) dataset, but extrapolated back to 1979 based on the annually-increasing $\mathrm{CH}_{4}$ at ground level. Note that we did not elect to use the concurrent $\mathrm{CH}_{4}$ distributions from the Nimbus 7 Stratosphere and Mesosphere Sounder (SAMS) experiment because they only extended down to about the 20-hPa level (Jones and Pyle, 1984). A similar first-order correction for the interfering emissions from stratospheric aerosols was developed based on the $5.26 \mu \mathrm{m}$ aerosol extinctions of March/May 1996 from HALOE, but then extrapolated back to 1979 based on the ratio of the SAGE I extinctions at $1 \mu \mathrm{m}$ for 1979 to the corresponding SAGE II extinctions of 1996. A minor extrapolation was also performed to convert the HALOE extinctions from 5.26 to $6.9 \mu \mathrm{m}$. However, the near-background aerosols of the LIMS time period have only a minor effect for the forward radiance model of its $\mathrm{H}_{2} \mathrm{O}$ channel. On the other hand, the accounting for $\mathrm{CH}_{4}$ leads to a reduction of tropical $\mathrm{H}_{2} \mathrm{O}$ mixing ratios by $15 \%$ between about 40 to $7 \mathrm{hPa}$. Effects of horizontal temperature gradients along the view path for the tangent-layer have also been accounted for to first order within the V6 algorithm (Remsberg et al., 2004).

The $\mathrm{V} 6 \mathrm{H}_{2} \mathrm{O}$ retrievals are based on a downward, onionpeeling approach, rather than an optimal estimation procedure. Anomalies in the retrieved profiles are exposed, as a result. Retrievals began where signal-to-noise $(\mathrm{S} / \mathrm{N})$ values for the radiances exceed a value of 1.5 - in the lower mesosphere. Temperatures in the mesosphere and to near the stratopause are slightly warmer than those of V5 because of (1) improvements in knowledge of the attitude of the Nimbus 7 spacecraft and its effects on the registration of the LIMS radiance profiles with pressure-altitude, and of (2) a greater accuracy with pressure and temperature in the development of the $\mathrm{CO}_{2}$ and the (interfering) ozone emissivity tables for the LIMS forward model for $T(p)$ (see Remsberg et al., 2004). A warmer atmospheric temperature for the tangent layer means that more of the observed radiance in the $\mathrm{H}_{2} \mathrm{O}$ channel is explained by the Planck Blackbody function as opposed to the infrared transmittance along the view path, which depends on the amount of $\mathrm{H}_{2} \mathrm{O}$ itself (see Eqs. (1) and (2) in Gille and Russell, 1984). Therefore, the retrieved values of $\mathrm{V}_{6} \mathrm{H}_{2} \mathrm{O}$ begin several layers lower than for V5. A constant $\mathrm{H}_{2} \mathrm{O}$ value of 6.5 ppmv was used in the LIMS forward radiance model to estimate the effects of water vapor radiance above the first retrieved layer. That assumed value is based on observations of $\mathrm{H}_{2} \mathrm{O}$ for the lower mesosphere from HALOE and MLS and from ground-based microwave measurements of the 1990s, with a slight downward adjustment for the lower values of $\mathrm{CH}_{4}$ and their oxidation to $\mathrm{H}_{2} \mathrm{O}$ for the 1978/79 period (Remsberg et al., 1984). 


\subsection{LIMS V6 zonal mean distributions of $\mathrm{H}_{2} \mathrm{O}$}

Figure 2a is the zonally-averaged distribution of $\mathrm{V} 6 \mathrm{H}_{2} \mathrm{O}$ for 15 November 1978 from its descending (north-to-south or local nighttime) orbital segments. General features that are apparent are: (1) the increase of water vapor from the lower to the upper stratosphere due to the chemical conversion of $\mathrm{CH}_{4}$ to water vapor with altitude, (2) the increase of water vapor in the lower stratosphere from near the Equator to higher latitudes or from the entry region for the dry air of the stratosphere to a region of more well-mixed air, and (3) a region of rapid increase from the "tropical hygropause" to just below the tropopause near $100 \mathrm{hPa}$, where the water vapor begins to increase rapidly. In addition, many of the low altitude portions of the tropical profiles were cutoff due to their low signal levels in the tangent layer. A first-order screening was also conducted for the presence of the interfering emissions from clouds, as evaluated based on the character of the corresponding LIMS ozone profiles that are affected very little by the increasing water vapor of the upper troposphere (Remsberg et al., 2007). Radiance contamination due to clouds is prevalent near the tropical tropopause. Those scan segments were screened out during the generation of the Level 2 dataset, leading to values in the tropics that may not be representative of the zonal mean even several kilometers higher. Notably, more tropical scans extend to lower altitudes on 15 November than is the case for most days.

Only a very few (less than 10) middle latitude, correlative water vapor profiles were obtained during 1978/79 for the purpose of validating the LIMS $\mathrm{H}_{2} \mathrm{O}$ profiles. Those few comparisons indicate that the LIMS V6 values are higher by 10 to $15 \%$ from about 10 to $70 \mathrm{hPa}$, but within the estimated accuracies of about $\pm 20 \%$ for both the comparison measurements (Russell et al., 1984) and the LIMS V6 data themselves (see also Sect. 3). Consequently, in this report we have opted to show qualitative comparisons of the zonal mean distributions of LIMS V6 versus those from Aura MLS that have been validated more extensively. The MLS Version $2.2 \mathrm{H}_{2} \mathrm{O}$ distributions are based on profiles having a vertical resolution in the stratosphere $(\sim 3-4 \mathrm{~km})$ that is comparable to that of LIMS V6. Precision of individual MLS stratospheric $\mathrm{H}_{2} \mathrm{O}$ profiles is about $5 \%$, and accuracy is of the order of $10 \%$ (Lambert et al., 2007).

Figure $2 \mathrm{~b}$ is a plot of MLS V2.2 stratospheric $\mathrm{H}_{2} \mathrm{O}$ for 15 November 2004, based on data that were accessed from the MLS Website (http://mls.jpl.nasa.gov/). The period of 2004/05 of the MLS data was selected for comparison because the distribution of $\mathrm{H}_{2} \mathrm{O}$ is affected somewhat by the QBO-induced circulations of the lower stratosphere and the tropical winds were changing from a westerly to an easterly QBO phase, as was the case for the LIMS period (Fueglistaler and Haynes, 2005). Although MLS $\mathrm{H}_{2} \mathrm{O}$ extends to near the mesopause, Fig. $2 b$ is restricted to the same pressure-altitude domain as that of LIMS in Fig. 2a. MLS data extend from $83^{\circ} \mathrm{S}$ to $83^{\circ} \mathrm{N}$ latitude, whereas the LIMS
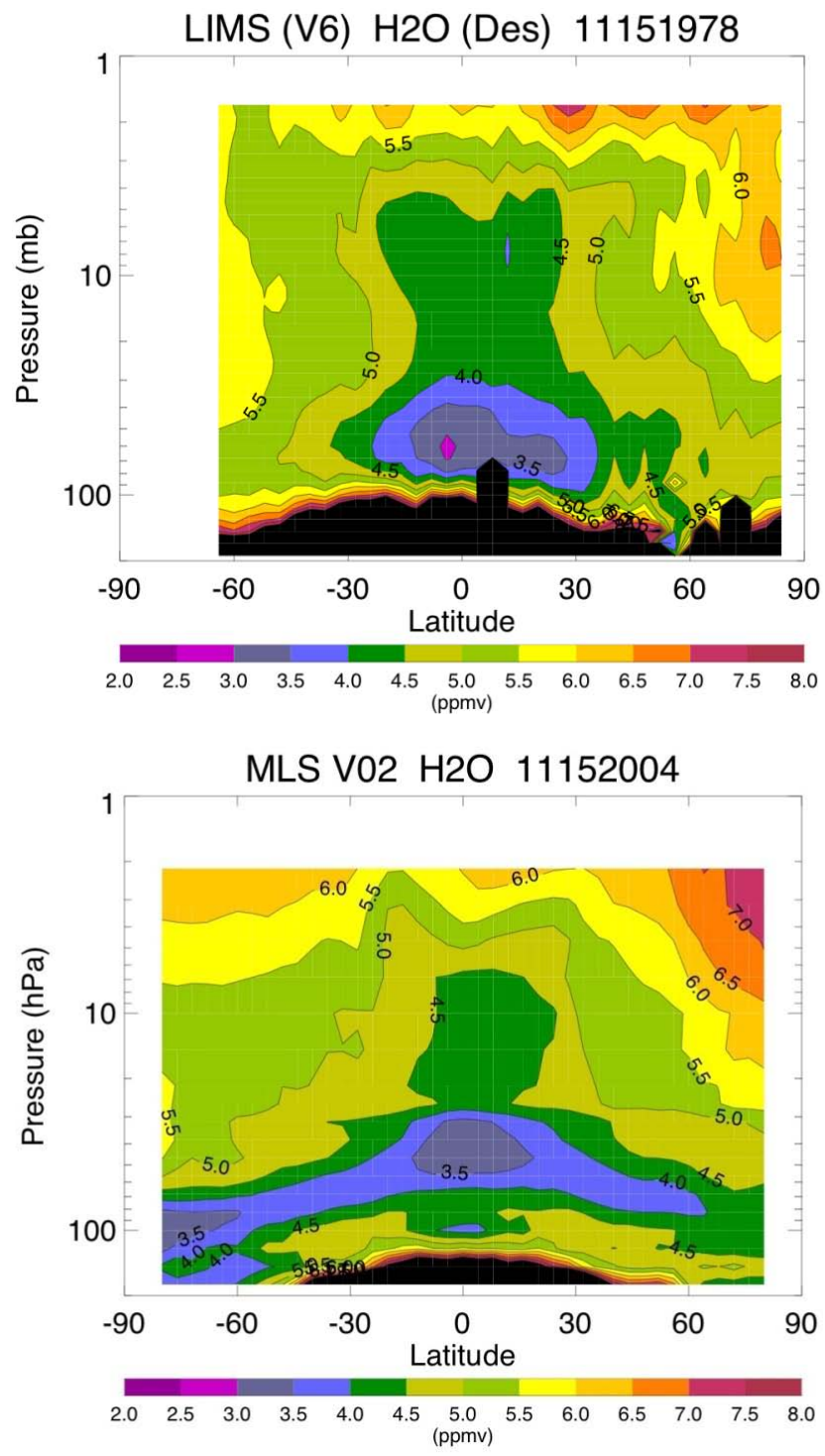

Fig. 2. (a) Zonal mean of LIMS V6 descending orbital (nighttime) $\mathrm{H}_{2} \mathrm{O}$ for 15 November 1978. Contour interval is 0.5 ppmv. (b) Zonal mean of MLS V2.2 $\mathrm{H}_{2} \mathrm{O}$ for 15 November 2004.

plot covers only from $64^{\circ} \mathrm{S}$ to $84^{\circ} \mathrm{N}$. It is noted that there is a vertical oscillation in the MLS v2.2 $\mathrm{H}_{2} \mathrm{O}$ distribution near $30 \mathrm{hPa}$ that stretches across most latitudes; that feature is an artifact due to departures from a linear signal response at that level. The MLS data were smoothed to first order according to the prescription in Lambert et al. (2007), prior to the generation of Fig. $2 b$.

The patterns of zonally-averaged water vapor agree well in most respects between LIMS and MLS, and their absolute values agree within about $10 \%$ in the middle stratosphere. MLS has values at $3 \mathrm{hPa}$ that are slightly larger than those of LIMS, a finding that is consistent with the fact that $\mathrm{CH}_{4}$ has been increasing in the stratosphere since the LIMS time period (Rohs et al., 2006). The respective meridional gradients 
of $\mathrm{H}_{2} \mathrm{O}$ are largest in the subtropics of the middle stratosphere, which is characteristic of the net transport of the Brewer/Dobson circulation plus the slow chemical conversion of $\mathrm{CH}_{4}$ to $\mathrm{H}_{2} \mathrm{O}$ with altitude. The altitudes of the tropical hygropause and the magnitudes of the minimum water vapor are also similar for the LIMS and MLS distributions of Fig. 2, indicating that the effects of the finite FOV and, in particular, the vertical weightings for the temperature and species are being handled properly in the forward radiance model of LIMS V6. That agreement is also an important indicator of the good accuracy of the LIMS V6 $T(p)$ and of the associated pressure registration of its water vapor radiances.

One can clearly see in Fig. 2 the effects of dehydration in the MLS data at $60^{\circ} \mathrm{S}$, but not in the LIMS cross section at the same latitude. This difference is most likely an indication of the expanded area and persistence of the cold, wintertime southern polar vortex and its associated polar stratospheric clouds (PSC) during the intervening 26 years. In fact, Fig. 4.3 of WMO (2007) shows a time series of the average NCEP/NCAR reanalysis temperatures for $60-90^{\circ} \mathrm{S}$ at $100 \mathrm{hPa}$ in October. The average temperature was about $-61^{\circ} \mathrm{C}$ in 1979 compared with $-65^{\circ} \mathrm{C}$ in 2004 . At the very least, the colder temperatures of 2004 are in the proper direction to explain the dryer air recorded by MLS in November 2004. In Sect. 4 LIMS and MLS comparisons are shown for February and for May, so that one can also judge the level of agreement for the seasonal variations of their water vapor distributions.

As with LIMS V5, no corrections have been made for the vibrationally-excited (non-LTE) $\mathrm{H}_{2} \mathrm{O}$ emissions - the effects of which are most significant in the mesosphere during daytime but which extend down to the uppermost stratosphere, too (Mertens et al., 2002). Figure 3 shows that the retrieved, zonally-averaged daytime $\mathrm{V} 6 \mathrm{H}_{2} \mathrm{O}$ is larger than that for nighttime by about 0.8 to 0.4 ppmv in the upper stratosphere for 15 November. Although there are rather large variations in those differences with latitude, note that there is almost no difference poleward of about $60^{\circ} \mathrm{N}$ (twilight or darkness for both the LIMS ascending and descending orbital segments). The nighttime LIMS $\mathrm{H}_{2} \mathrm{O}$ distributions ought to be more accurate because the effect of any nonLTE bias is much smaller in the absence of sunlight. But, the effects of non-LTE emissions on the LIMS $\mathrm{V} 6 \mathrm{H}_{2} \mathrm{O}$ of the upper stratosphere are also complicated by the fixed $\mathrm{H}_{2} \mathrm{O}$ value of 6.5 ppmv that was used for both day and night in the LIMS forward model above the first retrieved layer. Thus, the day/night differences of the upper stratosphere are not strictly representative of the non-LTE effects. Day/night $\mathrm{H}_{2} \mathrm{O}$ differences at $10 \mathrm{hPa}$ and through the lower stratosphere are less than about $0.4 \mathrm{ppmv}$, but still of order 5 to $10 \%$. On the other hand, if one wants to obtain better detail about the daily, zonal variations and the transport of $\mathrm{H}_{2} \mathrm{O}$ for the lower stratosphere, it is reasonable to assemble both the ascending (daytime) and descending (nighttime) LIMS data.

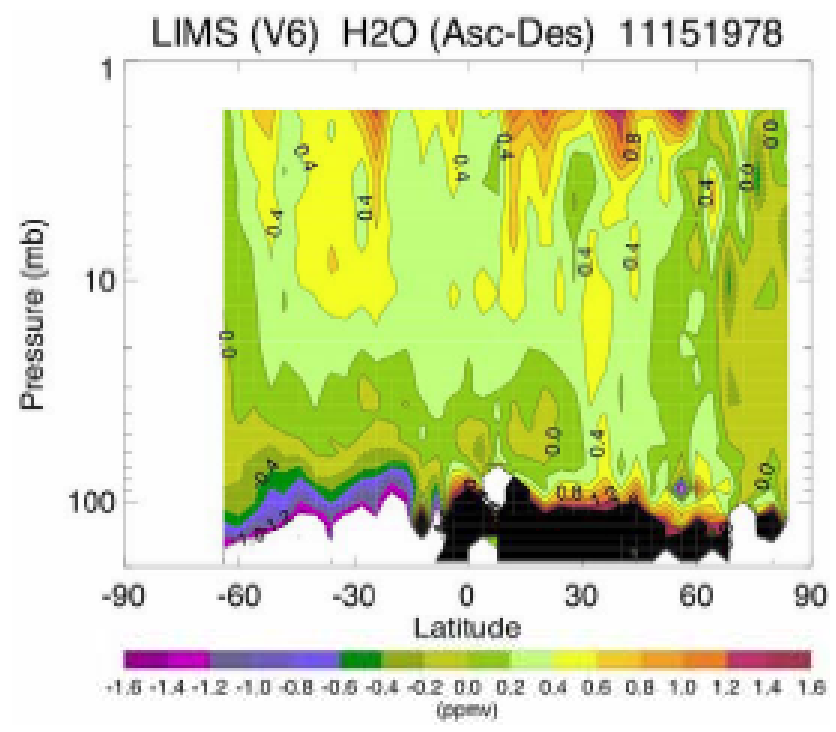

Fig. 3. Zonal-mean cross section of the ascending (day) minus descending (night) differences in LIMS $\mathrm{V} 6 \mathrm{H}_{2} \mathrm{O}$ for 15 November 1978. Contour interval is $0.2 \mathrm{ppmv}$.

\section{Estimates of error for single profiles}

Figure 4 is an estimate of the precision for a $\mathrm{V} 6 \mathrm{H}_{2} \mathrm{O}$ profile, as obtained from sets of about 6 scans along each of the orbital segments between $25^{\circ} \mathrm{S}$ and $35^{\circ} \mathrm{S}$ latitude on 1 February 1979 , i.e., for a season when the large-scale, zonal wave activity was small for the stratosphere. The profile points in Fig. 4 are actually based on the minimum standard deviation (SD) values from among all the sets of the separate descending (open diamonds) and then the ascending (solid diamonds) orbital segments. Even though there must be effects of atmospheric variability contained in them, those SD values are no worse than about $4 \%$ through much of the stratosphere. The much larger SD values near $100 \mathrm{hPa}$ may be due to not having screened effectively for the emissions from thin cirrus. Single profiles of $\mathrm{H}_{2} \mathrm{O}$ also have higher $\mathrm{SD}$ values near $1.3 \mathrm{hPa}$ because digitization and detector noise is significant for the measured radiances at and above that level.

Table 1 summarizes the calculations of precision (or random error) based on $\mathrm{S} / \mathrm{N}$, as well as the effects of systematic errors for a single $\mathrm{H}_{2} \mathrm{O}$ profile. Precision is no worse than about 5\% through most of the stratosphere, and it is a slight improvement from that of the V5 data - a consequence of the better vertical sampling for the radiances plus the use of a 5-interleave retrieval procedure for obtaining final V6 profiles (Remsberg et al., 2004). The calculated precisions are somewhat larger than the SD values of Fig. 4.

Estimates of the systematic errors in Table 1 were adopted from the simulation studies in Russell et al. (1984) for radiometric bias, $\mathrm{H}_{2} \mathrm{O}$ line parameter uncertainties $(8 \%)$, the main IFOV lobe, and the approximations for the forward model. The $\mathrm{H}_{2} \mathrm{O}$ profiles also have a bias of order 10 to $15 \%$ due 
Table 1. Estimates of Precision and Accuracy (in \%) for Profiles of LIMS V6 $\mathrm{H}_{2} \mathrm{O}$.

\begin{tabular}{lrrrrrr}
\hline Pressure (hPa) & 100 & 50 & 30 & 10 & 5 & 3 \\
\hline $\begin{array}{l}\text { Random } \\
\text { (or PRECISION) }\end{array}$ & 5 & 5 & 5 & 5 & 6 & 9 \\
Radiometric Bias & 5 & 5 & 5 & 5 & 5 & 5 \\
Temperature Bias & 16 & 18 & 11 & 8 & 14 & 15 \\
$\begin{array}{l}\text { (Amt. of } T \text { Bias) } \\
\mathrm{H}_{2} \mathrm{O} \text { Line }\end{array}$ & $(1.1 \mathrm{~K})$ & $(1.3 \mathrm{~K})$ & $(1.1 \mathrm{~K})$ & $(1.0 \mathrm{~K})$ & $(1.5 \mathrm{~K})$ & $(1.6 \mathrm{~K})$ \\
Parameters (8\%) & 8 & 8 & 8 & 8 & 8 & 8 \\
$\mathrm{O}_{2}$ Cross & 11 & 6 & 2 & 1 & 0 & 0 \\
Section (10\%) & & & & & & \\
Forward Model & 5 & 5 & 5 & 5 & 5 & 5 \\
Main IFOV Lobe & 15 & 15 & 5 & 5 & 5 & 5 \\
Root Sum Squares (RSS) of & 27 & 26 & 16 & 14 & 18 & 19 \\
Bias Errors (or ACCURACY) & & & & & & \\
\hline
\end{tabular}

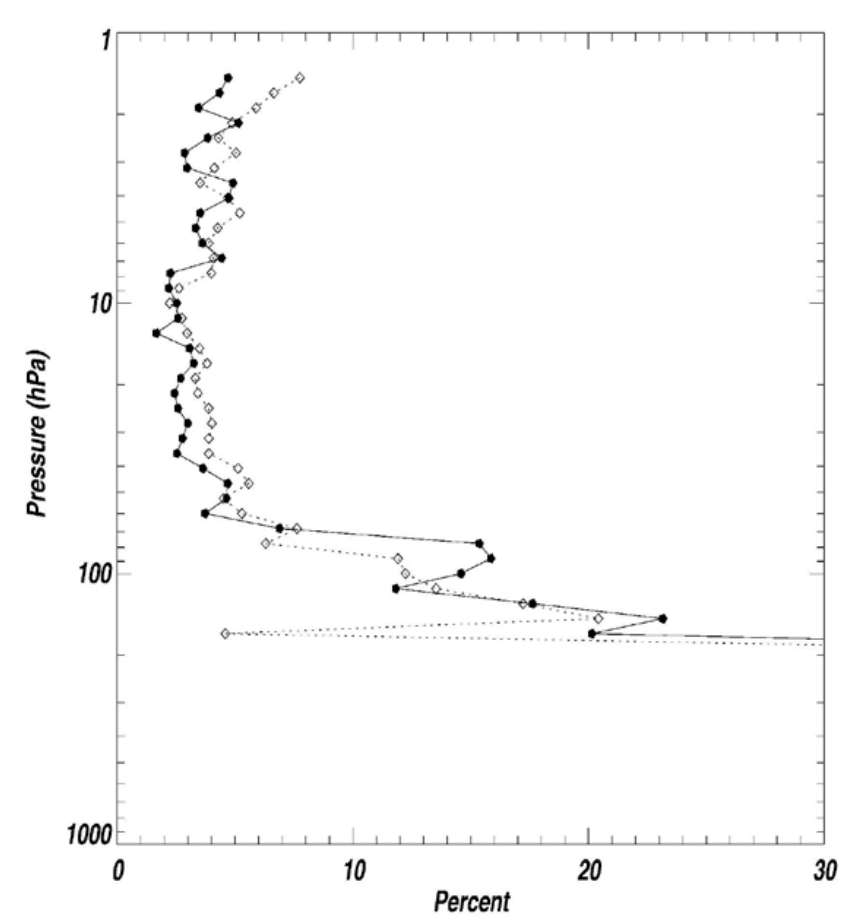

Fig. 4. Profiles of the minimum standard deviation (SD) values of LIMS V6 $\mathrm{H}_{2} \mathrm{O}$ (in \%) from its sets of descending (open diamonds) and ascending (solid diamonds) orbital crossings between $25^{\circ} \mathrm{S}$ and $35^{\circ} \mathrm{S}$ latitude on 1 February 1979.

to estimates of the V6 temperature biases from Remsberg et al. (2004, their Table 2, row g), which are less than $\pm 1.6 \mathrm{~K}$ as shown in parentheses in Table 1. Furthermore, there is no evidence that the estimated V6 $T(p)$ biases of Table 1 are all of the same sign. That finding is based on the V5 ver- sus rocketsonde/radiosonde $T(p)$ comparisons in Remsberg et al. (1984b), followed by the zonal mean, V6 minus V5 differences for $T(p)$ in Remsberg et al. (2007, their Fig. 3). Uncertainties from the model for the interfering, $\mathrm{O}_{2}$ continuum are of order $10 \%$, although the effect of that model is only important for the retrieved $\mathrm{H}_{2} \mathrm{O}$ from about 50 to $100 \mathrm{hPa}$. The root-sum-squares (RSS) of the bias errors that were evaluated are given in the bottom row of Table 1 and are of the order of $19 \%$ in the upper stratosphere, $15 \%$ in the middle stratosphere, and $26 \%$ in the lower stratosphere. Primary components of that total error are from the uncertainties of the main IFOV lobe and from the estimated temperature biases.

There are other sources of bias error that have not been fully characterized. For example, errors in the spatial side lobes of the IFOV function have not been verified, but their net effects appear to be small based on the quality of the V6 $\mathrm{H}_{2} \mathrm{O}$ distributions. Small uncertainties are present from the interfering aerosol emission of the lower stratosphere. The distribution of that emission varies with altitude and latitude, and it is representative of the near background aerosol layer of 1978/79. It is also noted that the same monthly and zonally-averaged distribution of aerosol emission was used for making a correction in the forward model for all months of the LIMS dataset. Biases for the interfering $\mathrm{CH}_{4}$ have their largest effect in the middle to lower stratosphere at tropical latitudes, but they lead to errors in $\mathrm{H}_{2} \mathrm{O}$ that are no greater than a few percent. There are also small biases in the retrieved $\mathrm{H}_{2} \mathrm{O}$ values at 1.3 to about $2.0 \mathrm{hPa}$ as a result of assuming the constant mixing ratio of $6.5 \mathrm{ppmv}$ for the forward model above the top retrieved layer. Some sources of bias error (such as that from temperature) also vary slightly according to the atmospheric state. In general, the RSS values of Table 1 are considered as worst case scenario estimates of the true total bias error for a single profile. Finally, the major 
stratospheric components of the aggregate $(\sim 10 \%)$ bias error profile for the $\mathrm{MLS} \mathrm{H}_{2} \mathrm{O}$ data used for comparison are from pointing uncertainties, forward model assumptions, and the optimal estimation formulation for its retrieval (Lambert et al., 2007).

\section{LIMS/MLS water vapor comparisons for February and May}

Figure $5 \mathrm{a}, \mathrm{b}$ is a comparison of the zonally-averaged $\mathrm{H}_{2} \mathrm{O}$ distributions for 15 February from LIMS in 1979 versus that from MLS in 2005. The agreement between the two is similar to that of November (Fig. 2), except for the region of the hygropause which is nearer to the tropopause in February than in November. Specifically, the tropical minimum for 15 February is near $50 \mathrm{hPa}$ to $70 \mathrm{hPa}(\sim 20$ to $18 \mathrm{~km})$ from LIMS but is near $80 \mathrm{hPa}$ to $100 \mathrm{hPa}(\sim 17.5$ to $16 \mathrm{~km})$ from MLS. Very few of the tropical LIMS profiles actually extend to $100 \mathrm{hPa}$, and it is very likely that those few still contain effects of residual emissions from thin cirrus. Limb infrared measurements are very sensitive to emissions from clouds, while the microwave measurements are much less so. Further, when the finite FOV measurements of LIMS are nearing the tropopause, the associated retrieved $\mathrm{H}_{2} \mathrm{O}$ will have a high bias even for clear skies because of the sharp increase in the water vapor of the upper troposphere. Therefore, one should be cautious about interpreting the LIMS $\mathrm{H}_{2} \mathrm{O}$ within about $2 \mathrm{~km}$ of the tropopause, or when lower than about $18 \mathrm{~km}$ in the tropics to about $13 \mathrm{~km}$ at high latitudes.

In the uppermost stratosphere and at high latitudes of the winter hemisphere the MLS $\mathrm{H}_{2} \mathrm{O}$ is greater than that of LIMS V6 by 0.5 to 1.0 ppmv, partly a result of the slow increase of atmospheric $\mathrm{CH}_{4}$ from 1978/79 to 2004/05 and its conversion to $\mathrm{H}_{2} \mathrm{O}$ in the upper stratosphere. The maximum values from the MLS data also support our choice of a constant value of $6.5 \mathrm{ppmv}$ for the LIMS $\mathrm{H}_{2} \mathrm{O}$ above the first retrieved layer in the lower mesosphere for the LIMS forward model. There are indications in the February MLS data of effects of descending air from near the stratopause to the middle stratosphere by its elevated values of $\mathrm{H}_{2} \mathrm{O}$ in the $\mathrm{NH}$ polar vortex. Conversely, the largest polar $\mathrm{H}_{2} \mathrm{O}$ from LIMS is centered near $30 \mathrm{hPa}$, and the temperatures are too warm in mid February for the occurrence of PSC and its emissions. It is noted that the mid-winter profile segments that were obviously contaminated by PSC have been screened out of the individual LIMS profiles, although residual effects may still be present. A listing of those occurrences is available in a separate file that is part of the archived LIMS V6 dataset.

Another important difference for the LIMS versus the MLS retrieval of water vapor is the high sensitivity of the LIMS radiances to temperature along its line-of-sight emissivity mass path. If there are slight errors in the horizontal (or vertical) temperature gradients, there will also be biases in the retrieved LIMS water vapor (see Table 1). Such bi-
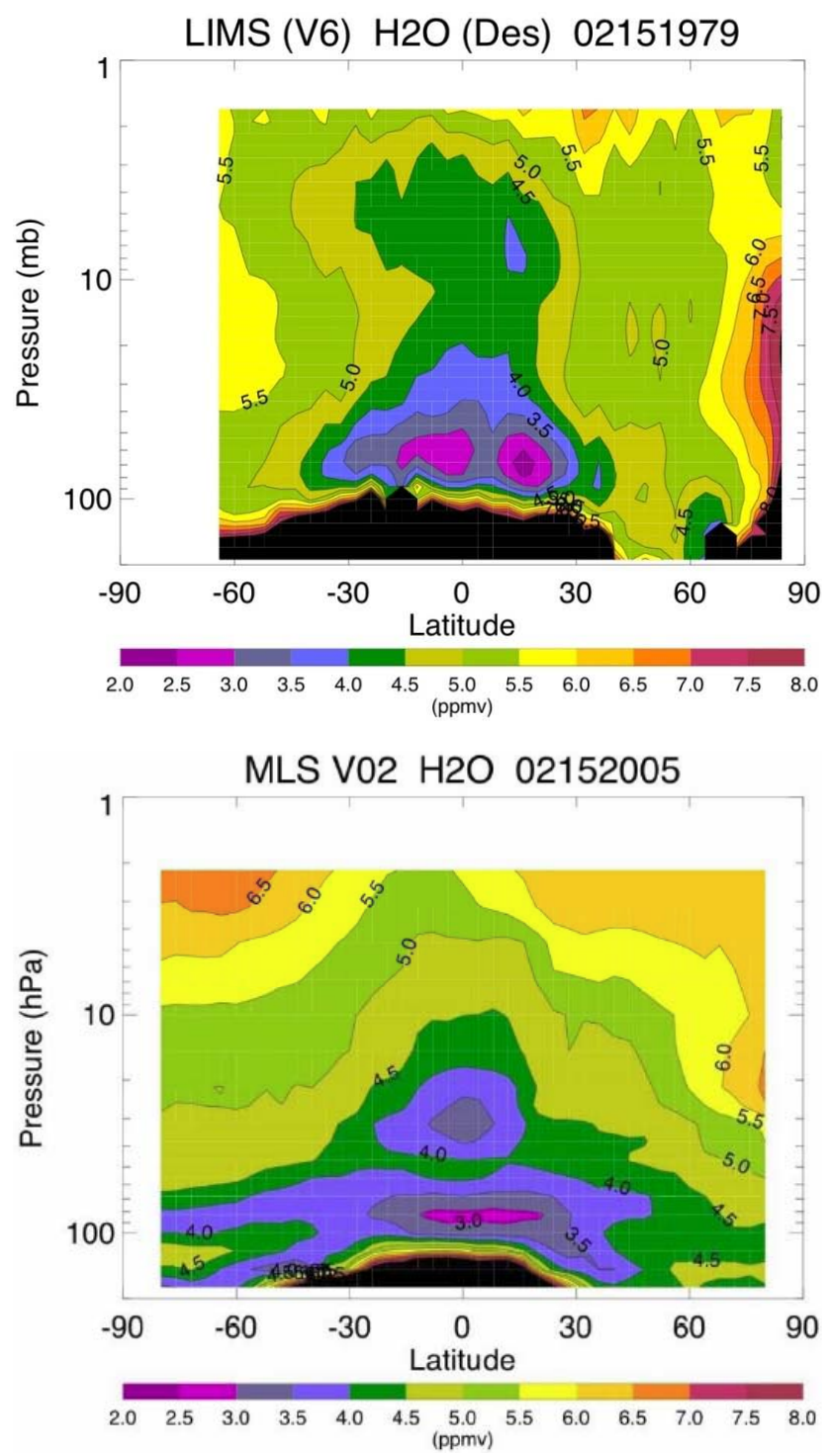

Fig. 5. As in Fig. 2, but (a) for LIMS V6 descending $\mathrm{H}_{2} \mathrm{O}$ of 15 February 1979 and (b) for MLS for 15 February 2005.

ases are a distinct possibility at the edges of the polar vortex and during the sudden stratospheric warming (SSW) periods of January and February 1979. It is presumed that errors in those gradients are the main cause of the apparent excess of polar $\mathrm{H}_{2} \mathrm{O}$ from LIMS, spanning from 8 to $80 \mathrm{hPa}$ in mid February.

Figure $6 \mathrm{a}, \mathrm{b}$ shows the LIMS/MLS comparisons for 16 May, and again the distributions are similar in most respects. However, Fig. 6a shows that there is an upward and poleward extension of relatively low values of LIMS water vapor $(<5.0 \mathrm{ppmv})$ at about $50^{\circ} \mathrm{S}, 3 \mathrm{hPa}$ for May, when there ought to be a slow descent of air from the lower mesosphere with higher $\mathrm{H}_{2} \mathrm{O}$ values. The MLS plot of Fig. 6b does not show a similar relative minimum. The region of $50^{\circ} \mathrm{S}, 3 \mathrm{hPa}$ is very near to the edge of the polar vortex, 

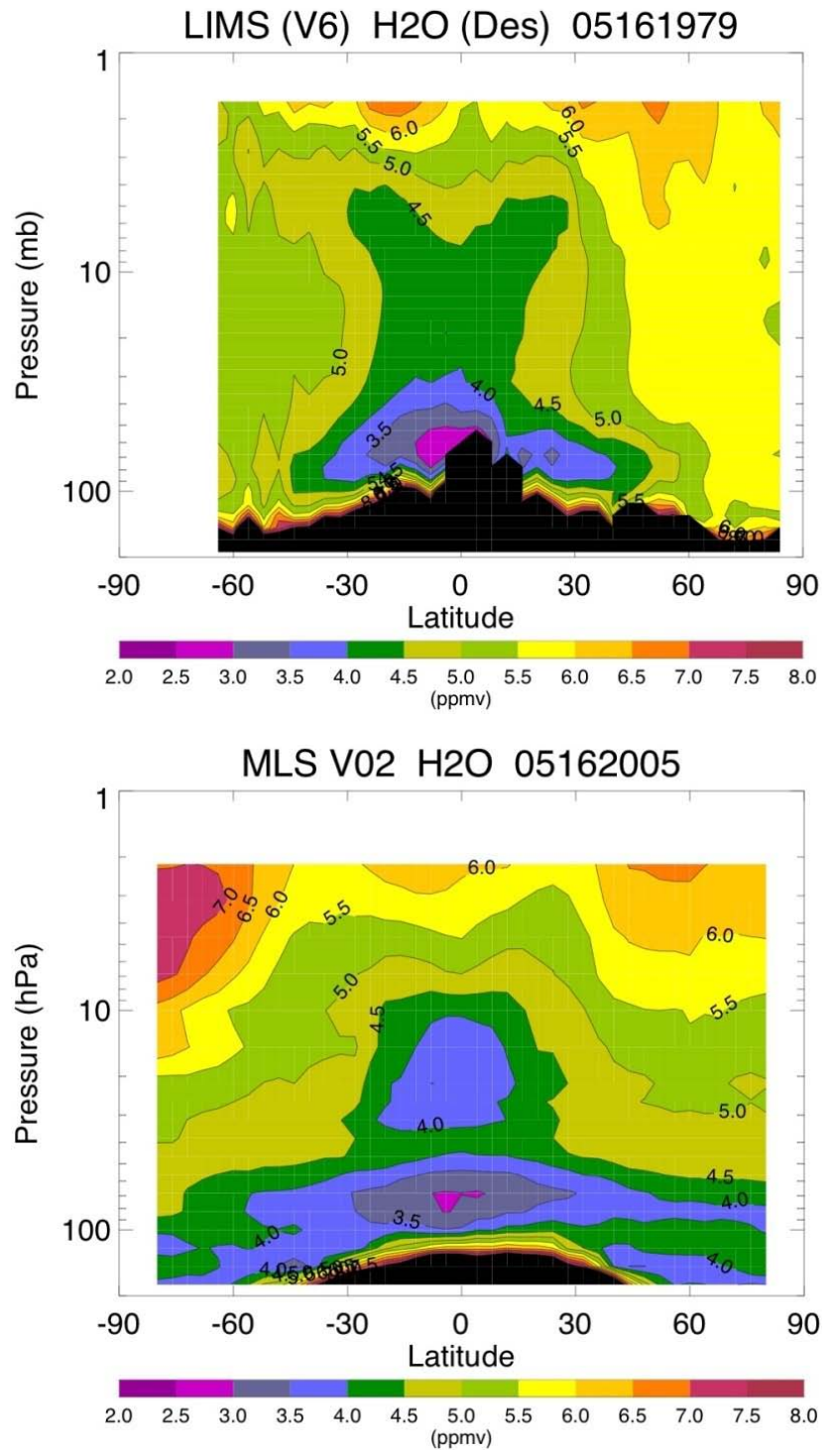

Fig. 6. As in Fig. 2, but (a) for LIMS V6 descending $\mathrm{H}_{2} \mathrm{O}$ of 16 May 1979 and (b) for MLS for 16 May 2005.

according to the enhanced meridional gradients of scaled potential vorticity (sPV) and as indicated in the equivalent latitude versus potential temperature (or EqL/ $\theta$ ) plots of the daily MLS water vapor for May (not shown, but viewable at http://mls.jpl.nasa.gov/).

Note that in the Northern Hemisphere there is only a hint of a relative minimum at $50^{\circ} \mathrm{N}, 3 \mathrm{hPa}$ in the LIMS plot of Fig. 2a for November, when the polar vortex has a similar seasonal configuration. The corresponding MLS plot of Fig. 2b shows an $\mathrm{H}_{2} \mathrm{O}$ distribution that is very much like that of LIMS. The good agreement between LIMS and MLS in November, but not in May, is explained as follows. The descending orbital segments of LIMS near $50^{\circ} \mathrm{S}$ for May were obtained when the Nimbus 7 satellite was viewing from above the South Pole and the LIMS tangent view path was northward or along the meridional temperature gradient (Remsberg et al., 1986). But because the true temperature field poleward of $64^{\circ} \mathrm{S}$ was not known, the $T(p)$ values at $64^{\circ} \mathrm{S}$ were merely extrapolated poleward for the LIMS emissivity mass path algorithm. Those extrapolated temperatures are too warm and not representative of the southern polar vortex region in May. Such a warm bias means that less of the total radiance in the water vapor channel is attributed to water vapor in the forward model, leading to the relative minimum in LIMS $\mathrm{H}_{2} \mathrm{O}$ that was retrieved. The corresponding zonal mean of the ascending LIMS $\mathrm{H}_{2} \mathrm{O}$ does not have a similar relative minimum at $50^{\circ} \mathrm{S}, 3 \mathrm{hPa}$, because the LIMS viewing direction for those orbital segments was more nearly along a line of latitude, and thus the temperature along its view path was known. For the Northern Hemisphere the LIMS temperatures were retrieved to $84^{\circ} \mathrm{N}$, and its orbital viewing geometry was also more nearly perpendicular to the temperature gradient. As a result, the LIMS temperatures are likely more accurate in the polar vortex region for the corresponding northern season (cf., Fig. 2a for November).

\section{Initial scientific findings from LIMS V6 water vapor}

The Stratospheric Processes and their Role in Climate (SPARC) Project Office has initiated a Re-assessment of the Water Vapor in the Upper Troposphere and Lower Stratosphere (UT/LS) study that is intended to be an update of Kley et al. (2000). The LIMS V6 dataset can be used to extend the historical record of the changes in UT/LS water vapor from the 1978/79 period (see also Rosenlof et al., 2001). As an example, the LIMS/MLS comparison plots of Figs. 2, 5, and 6 show the effects of the classic Brewer/Dobson (BD) circulation in their respective zonal-mean water vapor cross sections, at least for the middle and upper stratosphere.

The isolines of low water vapor mixing ratio above the tropopause are sloping toward higher pressures from low to high latitudes, in accord with a net meridional transport of air along isentropic surfaces. It also appears that the relatively dry air of the tropical lower stratosphere is being transported poleward more effectively in the MLS versus the LIMS $\mathrm{H}_{2} \mathrm{O}$ cross sections. Note that it is presumed that the patterns of the respective, zonal-mean MLS and LIMS $\mathrm{H}_{2} \mathrm{O}$ distributions are correct. Such differences may be an important tracer diagnostic for a climatological change in the meridional transport of the lower stratosphere ( $\mathrm{Li}$ et al., 2008; Thompson and Solomon, 2009; Tuck et al., 1997). For instance, an increase in the eddy heat flux due to wave activity will accelerate the BD circulation and lead to lower zonal mean cold-point temperatures at the tropical tropopause. More specifically, Dhomse et al. (2008) reported on a distinct anti-correlation between tropical water vapor values from 16 to $20 \mathrm{~km}$ and the September to February eddy heat flux at $50 \mathrm{hPa}$ of both hemispheres. They showed that the tropical temperature anomalies were cold and the eddy heat flux was 
enhanced during the period of the MLS measurements. On the other hand, their overall tropical temperature anomalies were warm during the time of the LIMS observations, indicating a corresponding reduction in the eddy heat flux and strength of the associated BD circulation.

Differences near $60^{\circ} \mathrm{S}$ in the MLS and LIMS $\mathrm{H}_{2} \mathrm{O}$ of Fig. 2 for the lower stratosphere indicate the effects of enhanced dehydration toward the outer regions of the southern polar vortex in the decades since the Nimbus 7 LIMS experiment. A more complete examination of the state of the Southern Hemisphere, polar winter stratosphere of 1978 should be undertaken to estimate the effects of dehydration at that time and for comparison with the measured values from LIMS in November and late October 1978.

The sequence of MLS water vapor of February, May, and then November (Figs. 5b, 6b, and 2b) indicates an annual cycle in $\mathrm{H}_{2} \mathrm{O}$ in the lower tropical stratosphere, the socalled "tape recorder" response first described by Mote et al. (1996). In other words, the location and movement of the MLS hygropause is in good accord with an annual cycle for $\mathrm{H}_{2} \mathrm{O}$, which has its minimum at the cold tropopause in February and is then carried upward through the rest of the year. Figure 7 a shows the 7-month time series of the daily-average, LIMS V6 descending $\mathrm{H}_{2} \mathrm{O}$ scans between $10^{\circ} \mathrm{S}$ to $10^{\circ} \mathrm{N}$ but plotted from 10 to only $50 \mathrm{hPa}$ or to near the lower limit of its signal-to-noise for the tangent layers of the tropics. No more than one or perhaps a very few LIMS scans were obtained at $10^{\circ} \mathrm{S}$ to $10^{\circ} \mathrm{N}$ on those days where the low altitude profile segments become white. For the 14 days when LIMS made no scans the average value from the previous day was plotted. Note that time series of the mixing ratios are shown rather than mixing ratio anomalies because there is less than one complete year of data for defining the annual averages; thus, amplitudes of the "annual" anomalies are underestimated at most pressure levels.

A "tape recorder" signal is evident above the 30-hPa level by the rightward, positive slope of the color bands with time in Fig. 7a. Such is not the case in the tropical lower stratosphere. Minimum values of the LIMS $\mathrm{H}_{2} \mathrm{O}$ occur in January/February, and the upward excursion of low water vapor mixing ratios to above the $30-\mathrm{hPa}$ level at this time may be a consequence of an enhanced extratropical, wintertime wave forcing for the ascent of the BD circulation (Solomon et al., 1986). The associated LIMS time series of the zonal average $T(p)$ is in Fig. 7b, and it indicates an upward extension of colder values at the same time. There is no clear evidence that the low values of the LIMS $\mathrm{H}_{2} \mathrm{O}$ are a result of a warm bias in the temperatures used for the $\mathrm{H}_{2} \mathrm{O}$ retrievals; on the contrary, the January/February LIMS values are colder by several degrees at 30 and $50 \mathrm{hPa}$ compared with other observed Equatorial temperatures (Randel et al., 2002). However, it is difficult to rule out a low bias in $\mathrm{H}_{2} \mathrm{O}$ due to the finite FOV effects of the LIMS $\mathrm{H}_{2} \mathrm{O}$ channel. Remsberg and Bhatt (1996) found that there was a wintertime encroachment of subtropical air to near the Equator near $20 \mathrm{hPa}$ in 1978/79.
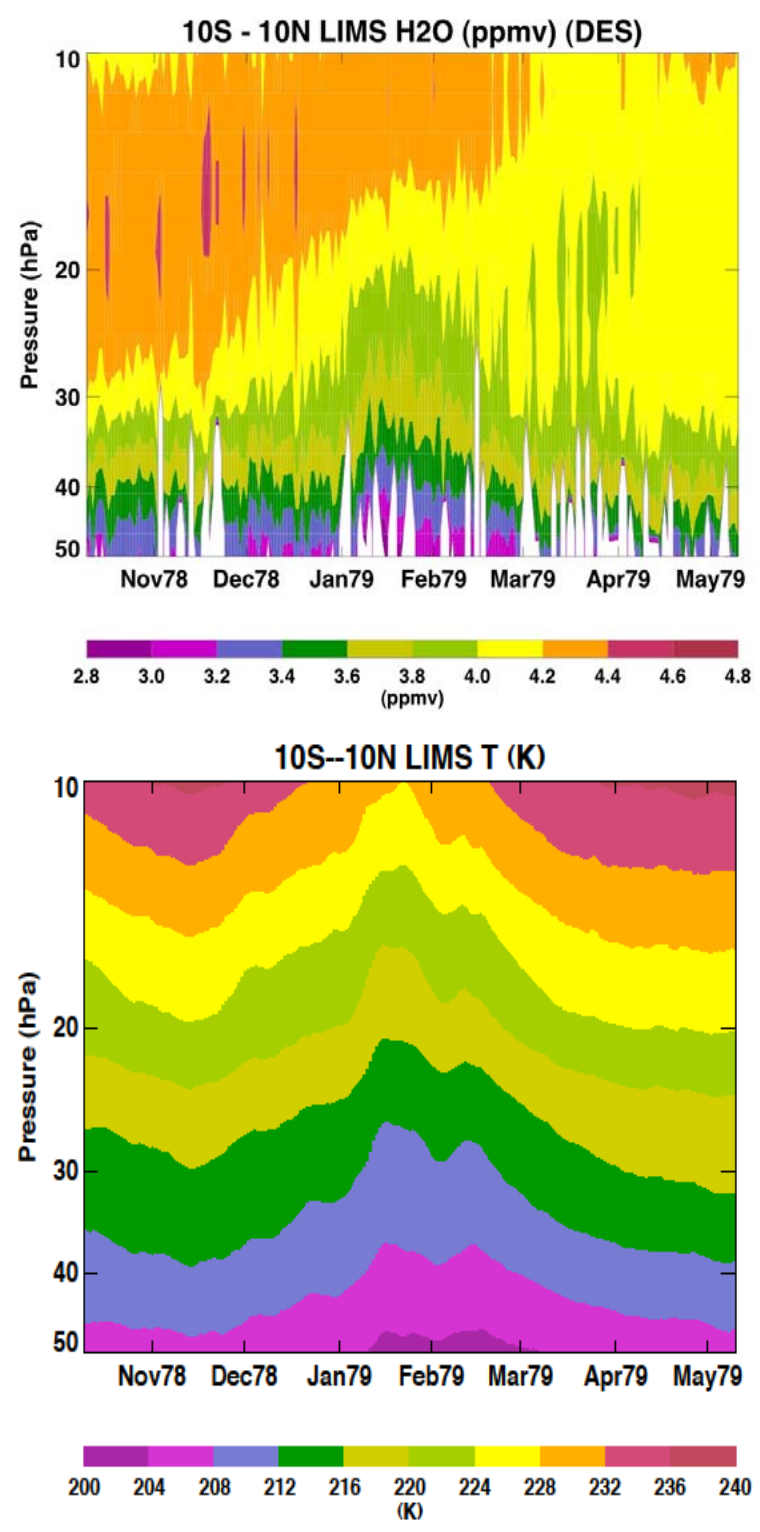

Fig. 7. (a) Time series of zonally-averaged, descending (DES) LIMS V6 $\mathrm{H}_{2} \mathrm{O}$ mixing ratio (in ppmv) for $10^{\circ} \mathrm{S}$ to $10^{\circ} \mathrm{N}$ and from 50 to $10 \mathrm{hPa}$; color contour increment is $0.2 \mathrm{ppmv}$ and plot extends only to 25 May 1979. (b) As in (a), but for LIMS V6 temperatures with a color change every $4 \mathrm{~K}$. Tic marks on the abscissa denote Day 15 of each month.

The time series of LIMS $\mathrm{H}_{2} \mathrm{O}$ averaged between $10^{\circ} \mathrm{S}$ and $6^{\circ} \mathrm{N}$ is nearly unchanged from that of $10^{\circ} \mathrm{S}$ to $10^{\circ} \mathrm{N}$, however. Finally, it is likely that the weakening of the vertical LIMS $\mathrm{H}_{2} \mathrm{O}$ gradient in Fig. 7a from March through May and 30 to $10 \mathrm{hPa}$ is a consequence of the meridional mixing of air during the transition from QBO westerlies to easterlies. Notably, Schoeberl et al. (2008, their Fig. 6a) found a similar blurring of the MLS $\mathrm{H}_{2} \mathrm{O}$ tape recorder signal for 2007.

Visual inspections of the LIMS water vapor values in the middle stratosphere for November, February, and May 
(Figs. 2, 5, and 6) indicate slightly larger values at middle latitudes in the northern than in the Southern Hemisphere, in accord with findings from aircraft data for non-vortex air (Kelly et al., 1990). In other words, there is a slight hemispheric asymmetry in the $\mathrm{H}_{2} \mathrm{O}$ values, most likely due to larger descent rates for polar air from the upper to the middle stratosphere in the Northern Hemisphere followed by meridional mixing from polar to middle latitudes. There may also be a northern subtropical contribution from the relatively large "entry-level $\mathrm{H}_{2} \mathrm{O}$ " ( or $\left[\mathrm{H}_{2} \mathrm{O}\right]_{e}$ ) associated with the summer monsoon circulation (Jackson et al., 1998). It is less likely that there is a mid-stratosphere influence in the Southern Hemisphere due to the wintertime polar dehydration over Antarctica (Mote, 1995).

Earlier estimates of $\left[\mathrm{H}_{2} \mathrm{O}\right]_{e}$ from LIMS by Jones et al. (1986) and Hansen and Robinson (1989) must be revised upward because of the greater values of the $\mathrm{V}^{6} \mathrm{H}_{2} \mathrm{O}$. For example, using the descending LIMS V6 $\mathrm{H}_{2} \mathrm{O}$ and the SAMS $\mathrm{CH}_{4}$ for the months of January through May 1979, a value of $6.8 \pm 0.3$ ppmv is obtained now for the quantity $2 \mathrm{CH}_{4}+\mathrm{H}_{2} \mathrm{O}$ at $40^{\circ} \mathrm{N}$ and between 3 and $10 \mathrm{hPa}$. Tropospheric $\mathrm{CH}_{4}$ and, thus, $\left[\mathrm{CH}_{4}\right]_{e}$ was about $1.5 \mathrm{ppmv}$ in 1978/79 (Rohs et al., 2006), so a value of $3.8 \pm 0.3 \mathrm{ppmv}$ is inferred for $\left[\mathrm{H}_{2} \mathrm{O}\right]_{e}$ at $40^{\circ} \mathrm{N}$. Mid to upper stratospheric values of $2 \mathrm{CH}_{4}+\mathrm{H}_{2} \mathrm{O}$ at $40^{\circ} \mathrm{S}$ are about $6.5 \mathrm{ppmv}$, so $\left[\mathrm{H}_{2} \mathrm{O}\right]_{e}$ is smaller there by 0.3 ppmv or only about 3.5 ppmv. This range of $\left[\mathrm{H}_{2} \mathrm{O}\right]_{e}$ values agrees well with that inferred from both the in situ and the satellite measurements of the late 1980s and the 1990s (see Table 2.4 of Kley et al., 2000). It is also qualitatively consistent with the warm anomalies for the cold-point tropopause temperatures of the late 1970s.

Both the vertical and along-orbit sampling of the LIMS $\mathrm{H}_{2} \mathrm{O}$ dataset represent significant improvements with the V6 profiles. For this reason daily water vapor fields on pressure surfaces exhibit good continuity, making it possible to resolve some of the details of the variations and the large-scale transport of water vapor with altitude, latitude, and longitude. As an example, Fig. 8a shows the distribution of LIMS $\mathrm{H}_{2} \mathrm{O}$ of 7 February 1979 on the 31.6-hPa surface for the Northern Hemisphere, as generated from zonal Fourier analyses of the V6 profiles plus minor interpolations for their coefficients in time and onto grid spaces. One can see a region of low $\mathrm{H}_{2} \mathrm{O}(4.5 \mathrm{ppmv})$ at about the Greenwich meridian (or $0^{\circ} \mathrm{E}$ ) and $55^{\circ} \mathrm{N}$ latitude; it is co-located with temperatures near $195 \mathrm{~K}$ or just above the threshold for deposition to water ice. The associated plot of the LIMS geopotential height is in Fig. 8b. It shows the effects of underlying domes of high pressure over Siberia and the Aleutians, flanking an intense polar vortex region that is being drawn out toward lower latitudes. Qualitatively, there is a large-scale, counterclockwise circulation about the outer edge of the vortex, transporting lower values of water vapor toward the vortex from middle latitudes and peeling higher values of $\mathrm{H}_{2} \mathrm{O}$ from the vortex edge toward the middle latitudes. A more complete analysis of the transport of $\mathrm{H}_{2} \mathrm{O}$ is possible during this period using
LIMS V6 Water Vapor (ppmv)

Northern Hemisphere 31.6hPa 7 Feb 1979

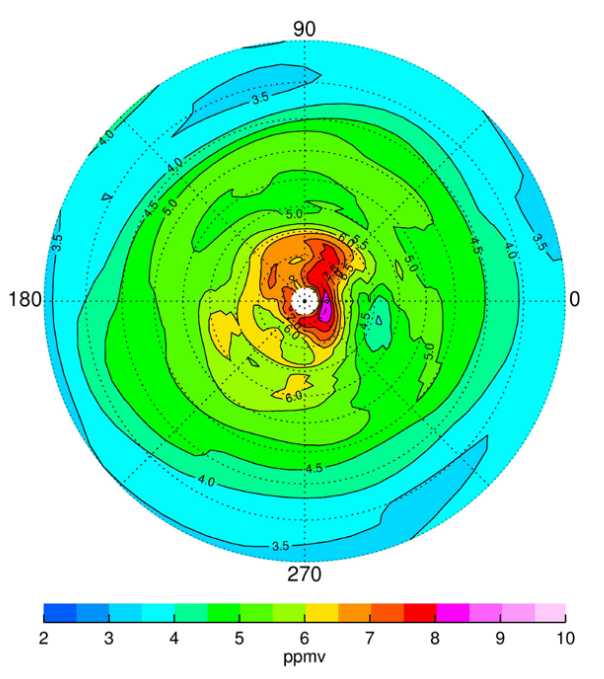

LIMS V6 Geop Height (km)

Northern Hemisphere 31.6hPa 7 Feb 1979

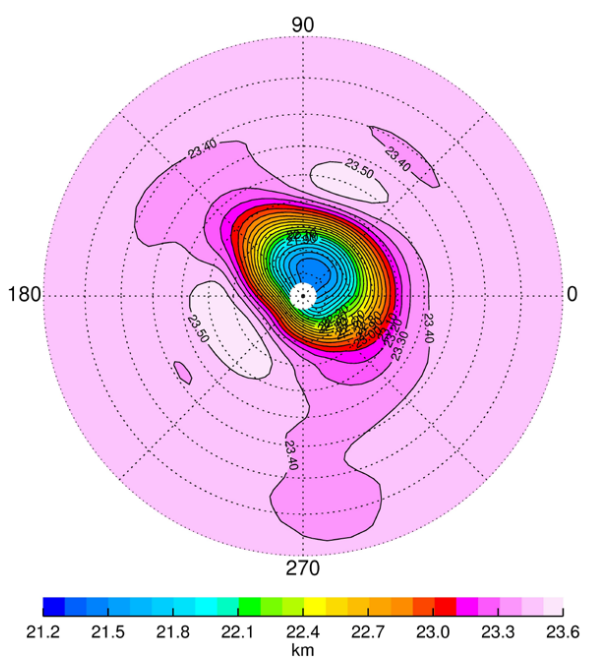

Fig. 8. Polar plot of LIMS V6 Northern Hemisphere data at $31.6 \mathrm{hPa}$ for 7 February $1979-$ (a) $\mathrm{H}_{2} \mathrm{O}$ with a contour interval of 0.5 ppmv; (b) geopotential height from 21.2 to 23.6 with a contour interval of $0.1 \mathrm{gpkm}$.

sequences of daily plots of the water vapor along with calculated wind fields from the concurrent surface maps of the LIMS geopotential heights.

The LIMS instrument and measurement concept is also the prototype for the Sounding of the Atmosphere using Broadband Emission Radiometry (SABER) satellite experiment (Russell et al., 1999), which began measurements in January 2002 and is still operating in 2009. SABER measures water vapor radiance profiles from the tropopause (or cloud tops) to the upper mesosphere and with nearly a $2 \mathrm{~km}$ vertical resolution. Its algorithm for obtaining useful water vapor profiles is fashioned after that of LIMS V6, but with the important 
addition of a forward model for the non-LTE radiances of the mesosphere and the improvements for the retrieval of $\mathrm{H}_{2} \mathrm{O}$ profiles down into the stratosphere.

The SABER v1.07 algorithm gives water vapor values in the mesosphere that are too large, in part because of small but significant cold biases in the SABER $T(p)$ (Remsberg et al., 2008). The estimates of LIMS V6 accuracy in Table 1 clearly show that small biases in the temperature profile affect the LTE retrieval of water vapor from limb radiances in the 6.4 to $7.3 \mu \mathrm{m}$ spectral region. However, based on the good agreement between the LIMS V6 and the MLS water vapor distributions, there is every reason to expect that the SABER $\mathrm{H}_{2} \mathrm{O}$ profiles will be of better quality once the bias in the SABER $T(p)$ is accounted for (e.g., Feofilov et al., 2009). Multi-year, near global-scale studies of the transport of water vapor are anticipated from the LIMS, MLS, and SABER datasets.

\section{Conclusions}

The radiances of the Nimbus 7 LIMS experiment were reconditioned and new retrievals of them were conducted with a V6 algorithm to make its products more compatible with those of follow-on satellite experiments. Single profiles of the LIMS V6 $\mathrm{H}_{2} \mathrm{O}$ have improved precision (5\%) and accuracies $(19 \%$ at $3 \mathrm{hPa}, 14 \%$ at $10 \mathrm{hPa}$, and $26 \%$ at $50 \mathrm{hPa})$, as compared with the original V5 product. Qualitative comparisons with the Aura MLS V2.2 $\mathrm{H}_{2} \mathrm{O}$ reveal similar patterns and absolute values between about $70 \mathrm{hPa}$ and $3 \mathrm{hPa}$. However, one should be cautious about interpreting features in the LIMS V6 profiles of the lowermost stratosphere, in particular within about $2 \mathrm{~km}$ of the tropopause where the effects of residual emissions from cloud tops may still be present. The profile segments from about $3.0 \mathrm{hPa}$ to $1.3 \mathrm{hPa}$ contain day/night differences of order $0.6 \mathrm{ppmv}$ ( or $\sim 10 \%$ ), due to not having corrected for the effects of non-LTE emissions near to and above the stratopause.

The V6 Level 2 (profile) data can be obtained by ftp download from the Goddard Earth Sciences and Data Information Services Center (http://daac.gsfc.nasa.gov/) under the menu entitled "Remote Sensing Data". Individual LIMS V6 profiles have a point spacing of $0.375 \mathrm{~km}$. Their effective vertical resolution is $3.7 \mathrm{~km}$, primarily because of the finite FOV of the LIMS $\mathrm{H}_{2} \mathrm{O}$ channel. Retrievals were conducted for adjacent pairs of profiles along orbits, yielding an effective spacing of one profile per 1.6 degrees of latitude.

The good precision of the V6 profiles provides for daily surface maps of stratospheric water vapor for studies of its large-scale transport. Although accuracies for single profiles of the LIMS V6 $\mathrm{H}_{2} \mathrm{O}$ may be no better than about $15 \%$, the relative accuracies for its zonal mean distributions are much better than that. Analyses of $\mathrm{H}_{2} \mathrm{O}$ time series reveal an annual tropical tape recorder signal plus the effects of a dynamically-induced Brewer-Dobson circulation. Aver- age "entry-level" values for the LIMS V6 $\mathrm{H}_{2} \mathrm{O}$ vary from 3.5 ppmv as inferred from the data for the Southern Hemisphere versus 3.8 ppmv for the Northern Hemisphere.

Acknowledgements. We recognize John Gille and James Russell III (Co-PIs of the LIMS experiment) and the members of the original LIMS Project and Science Teams. The research leading to the improvement and generation of the LIMS V6 Level 2 water vapor dataset was conducted with funds from several NASA NRA proposals and with the consistent support of Jack Kaye of NASA Headquarters. The analyses in this manuscript were conducted with funds from the NASA NRA NNH08ZDA001N for the MAP Program administered by David Considine.

Edited by: W. Lahoz

\section{References}

Andrews, D. G., Holton, J. R., and Leovy, C. B.: Middle Atmosphere Dynamics, Academic Press, New York, 489 pp., 1987.

Butchart, N. and Remsberg, E. E., The area of the stratospheric polar vortex as a diagnostic for tracer transport on an isentropic surface, J. Atmos. Sci., 43, 1319-1339, 1986.

Chiou, E., Remsberg, E. E., Rodgers, C. D., Munro, R., Bevilacqua, R. M., McCormick, M. P., and Russell III, J. M.: Proposed reference model for middle atmosphere water vapor, Adv. Space Res., 18(9/10), 59-89, 1996.

Chiou, E. W., McCormick, M. P., McMaster, L. R., Chu, W. P., Larsen, J. C., Rind, D., and Oltmans, S.: Intercomparison of stratospheric water vapor observed by satellite experiments: stratospheric aerosol and gas experiment II versus limb infrared monitor of the stratosphere and atmospheric trace molecule spectroscopy, J. Geophys. Res., 98, 4875-4887, 1993.

Dhomse, S., Weber, M., and Burrows, J.: The relationship between tropospheric wave forcing and tropical lower stratospheric water vapor, Atmos. Chem. Phys., 8, 471-480, 2008,

http://www.atmos-chem-phys.net/8/471/2008/.

Feofilov, A. G., Kutepov, A. A., Pesnell, W. D., Goldberg, R. A., Marshall, B. T., Gordley, L. L., García-Comas, M., LópezPuertas, M., Manuilova, R. O., Yankovsky, V. A., Petelina, S. V., and Russell III, J. M.: Daytime SABER/TIMED observations of water vapor in the mesosphere: retrieval approach and first results, Atmos. Chem. Phys., 9, 8139-8158, 2009, http://www.atmos-chem-phys.net/9/8139/2009/.

Fueglistaler, S. and Haynes, P. H.: Control of interannual and longer-term variability of stratospheric water vapor, J. Geophys. Res., 110, D24108, doi:10.1029/2005JD006019, 2005.

Garcia, R. and Solomon, S.: A new numerical model of the middle atmosphere, 2. Ozone and related species, J. Geophys. Res., 99, 12937-12951, 1994.

Gille, J. C. and Russell III, J. M.: The limb infrared monitor of the stratosphere: experiment description, performance, and results, J. Geophys. Res., 89, 5125-5140, 1984.

Gille, J. C., Lyjak, L. V., and Smith, A. K.: The global residual mean circulation in the middle atmosphere for the northern winter period, J. Atmos. Sci., 44, 1437-1452, 1987.

Gray, L. J. and Pyle, J. A.: The semiannual oscillation and equatorial tracer distributions, Q. J. Roy. Meteorol. Soc., 112, 387-407, 1986. 
Hansen, A. R. and Robinson, G. D.: Water vapor and methane in the upper stratosphere: an examination of some of the Nimbus 7 measurements, J. Geophys. Res., 94, 8474-8484, 1989.

Jackson, D. R., Driscoll, S. J., Highwood, E. J., Harries, J. E., and Russell III, J. M.: Troposphere to stratosphere transport at low latitudes as studies using HALOE observations of water vapour 1992-1997, Q. J. Roy. Meteorol. Soc., 124, 169-192, 1998.

Jones, R. L. and Pyle, J. A.: Observations of $\mathrm{CH}_{4}$ and $\mathrm{N}_{2} \mathrm{O}$ by the NIMBUS 7 SAMS: a comparison with in situ data and twodimensional numerical model calculations, J. Geophys. Res., 89, 5263-5279, 1984.

Jones, R. L., Pyle, J. A., Harries, J. E., Zavody, A. M., Russell III, J. M., and Gille, J. C.: The water vapor budget of the stratosphere studied using LIMS and SAMS satellite data, Q. J. Roy. Meteorol. Soc., 112, 1127-1143, 1986.

Kelly, K. K., Tuck, A. F., Heidt, L. E., Loewenstein, M., Podolske, J. R., Strahan, S. E., and Vedder, J. F.: A comparison of ER2 measurements of stratospheric water vapor between the 1987 Antarctic and 1989 Arctic airborne missions, Geophys. Res. Lett., 17, 465-468, 1990.

Kerridge, B. J. and Remsberg, E. E.: Evidence from the limb infrared monitor of the stratosphere for nonlocal thermodynamic equilibrium in the nu 2 mode of mesospheric water vapour and the nu3 mode of stratospheric nitrogen dioxide, J. Geophys. Res., 94, 16323-16342, 1989.

Kley, D., Russell III, J. M., and Phillips, C. (eds.): SPARC Assessment of Upper Tropospheric and Stratospheric Water Vapour, World Climate Research Program (WCRP) Report No. 113, World Meteorological Organization (WMO) Technical Document 1043, 312 pp., 2000.

Lambert, A., Read, W. G., Livesey, N. J., Santee, M. L., Manney, G. L., Froidevaux, L., Wu, D. L., Schwartz, M. J., Pumphrey, H. C., Jimenez, C., Nedoluha, G. E., Cofield, R. E., Cuddy, D. T., Daffer, W. H., Drouin, B. J., Fuller, R. A., Jarnot, R. F., Knosp, B. W., Pickett, H. M., Perun, V. S., Snyder, W. V., Stek, P. C., Thurstans, R. P., P. A. Wagner, Waters, J. W., Jucks, K. W., Toon, G. C., Stachnik, R. A., Bernath, P. F., Boone, C. D., Walker, K. A., Urban, J., Murtagh, D., Elkins, J. W., and Atlas, E.: Validation of the Aura Microwave Limb Sounder middle atmosphere water vapor and nitrous oxide measurements, J. Geophys. Res., 112, D24S36, doi:10.1029/2007JD008724, 2007.

LeTexier, L., Solomon, S., and Garcia, R. R.: The role of molecular hydrogen and methane oxidation in the water vapour budget of the stratosphere, Q. J. Roy. Meteorol. Soc., 114, 281-296, 1998.

Li, F., Austin, J., and Wilson, J.: The strength of the BrewerDobson circulation in a changing climate: coupled chemistryclimate model simulations, J. Climate, 21, 40-57, 2008.

Mertens, C. J., Mlynczak, M. J., Lopez-Puertas, M., and Remsberg, E. E.: Impact of non-LTE processes on middle atmospheric water vapor retrievals from simulated measurements of 6.8 micrometer Earth limb emission, Geophys. Res. Lett., 29(9), 2-1-2-4, 2002.

Mote, P. W.: Reconsideration of the cause of dry air in the southern middle latitude stratosphere, Geophys. Res. Lett., 22, 20252028, 1995.

Mote, P. W., Rosenlof, K. H., Holton, J. R., Harwood, R. S., and Waters, J. W.: An atmospheric tape recorder: the imprint of tropical tropopause temperatures on stratospheric water vapor, J. Geophys. Res., 102, 3989-4006, 1996.

Randel, W., Chanin, M.-L., and Michaut, C. (eds.): SPARC In- tercomparison of Middle Atmosphere Climatologies, World Climate Research Program (WCRP) Report No. 116, World Meteorological Organization (WMO) Technical Document 1142, 96 pp., 2002.

Remsberg, E. E. and Bhatt, P. P.: Zonal variance of nitric acid vapor as an indicator of meridional mixing in the subtropical lower stratosphere, J. Geophys. Res., 101, 29523-29530, 1996.

Remsberg, E. E. and Russell III, J. M.: The near global distributions of middle atmospheric $\mathrm{H}_{2} \mathrm{O}$ and $\mathrm{NO}_{2}$ measured by the Nimbus 7 LIMS experiment, in: Transport Processes in the Middle Atmosphere, edited by: Visconti, G. and Garcia, R., Reidel, 87-102, 1987.

Remsberg, E. E., Russell III, J. M., and Wu, C.-Y.: An interim reference model for the variability of the middle atmosphere water vapor distribution, Adv. Space Res., 10(6), 51-64, 1990.

Remsberg, E. E., Russell III, J. M., Gordley, L. L., Gille, J. C., and Bailey, P. L.: Implications of the stratospheric water vapor distribution as determined from the NIMBUS 7 LIMS experiment, J. Atmos. Sci., 41, 2934-2945, 1984a.

Remsberg, E. E., Russell III, J. M., Gille, J. C., Gordley, L. L., Bailey, P. L., Planet, W. G., and Harries, J. E.: The validation of NIMBUS 7 measurements of ozone, J. Geophys. Res., 89, 51615178, 1984b.

Remsberg, E. E., Kurzeja, R. J., Haggard, K. V., Russell III, J. M., and Gordley, L. L.: Description of data on the Nimbus 7 LIMS Map Archive Tape - Ozone and Nitric Acid, NASA Tech. Paper No. 2625, available from NTIS, Springfield, VA, 71 pp., 1986.

Remsberg, E. E., Gordley, L. L., Marshall, B. T., Thompson, R. E., Burton, J., Bhatt, P., Harvey, V. L., Lingenfelser, G. S., and Natarajan, M.: The Nimbus 7 LIMS Version 6 radiance conditioning and temperature retrieval methods and results, J. Quant. Spectrosc. Ra., 86, 395-424, doi:10.1016/j.jqsrt.2003.12.007, 2004.

Remsberg, E., Lingenfelser, G., Natarajan, M., Gordley, L., Marshall, B. T., and Thompson, E.: On the quality of the Nimbus 7 LIMS version 6 ozone for studies of the middle atmosphere, J. Quant. Spectrosc. Ra., 105, 492-518, doi:10.1016/j.jqsrt.2006.12.005, 2007.

Remsberg, E. E., Marshall, B. T., Garcia-Comas, M., Krueger, D., Lingenfelser, G. S., Martin-Torres, J., Mlynczak, M. G., Russell III, J. M., Smith, A. K., Zhao, Y., Brown, C., Gordley, L. L., Lopez-Gonzalez, M. J., Lopez-Puertas, M., She, C.-Y., Taylor, M. J., and Thompson, R. E.: Assessment of the quality of the Version 1.07 temperature-versus-pressure profiles of the middle atmosphere from TIMED/SABER, J. Geophys. Res., 113, D17101, doi:10.1029/2008JD010013, 2008.

Rohs, S., Schiller, C., Riese, M., Engel, A., Schmidt, U., Wetter, T., Levin, I., Nakazawa, T., and Aoki, S.: Longterm changes of methane and hydrogen in the stratosphere in the period 1978-2003 and their impact on the abundance of stratospheric water vapor, J. Geophys. Res., 111, D14315, doi:10.1029/2005JD006877, 2006.

Rosenlof, K. H., Oltmans, S. J., Kley, D., Russell III, J. M., Chiou, E.-W., Chu, W. P., Johnson, D. J., Kelly, K. K., Michelsen, H. A., Nedoluha, G. E., Remsberg, E. E., Toon, G. C., and McCormick, M. P.: Stratospheric water vapor increases over the past half century, Geophys. Res. Lett., 28, 1195-1198, 2001.

Rothman, L. S., Rinsland, C. P., Goldman, A., Massie, S. T., Edwards, D. P., Flaud, J.-M., Perrin, A., Camy-Peyret, C., Dana, 
V., Mandin, J.-Y., Schroeder, J., McCann, A., Gamache, R. R., Wattson, R. B., Yoshino, K., Chance, K. V., Jucks, K. W., Brown, L. R., Nemtchinov, V., and Varanasi, P.: The HITRAN molecular spectroscopic database and HAWKS (HITRAN Atmospheric WorKStation): 1996 edition, J. Quant. Spectrosc. Ra., 60, 665710, 1998.

Russell III, J. M.: An interim reference model for the middle atmosphere water vapor distribution, Adv. Space Res., 7(9), 5-15, 1987.

Russell III, J. M., Gille, J. C., Remsberg, E. E., Gordley, L. L., Bailey, P. L., Fischer, H., Girard, A., Drayson, S. R., Evans, W. F. J., and Harries, J. E.: Validation of water vapor results measured by the limb infrared monitor of the stratosphere experiment on NIMBUS 7, J. Geophys. Res., 89, 5115-5124, 1984.

Russell III, J. M., Mlynczak, M. G., Gordley, L. L., Tansock, J., and Esplin, R.: An overview of the SABER experiment and preliminary calibration results, in Proceedings of the SPIE, 3756, 44th Annual Meeting, Denver, CO, 18-23 July, 277-288, 1999.

Schoeberl, M. R., Douglass, A. R., Stolarski, R. S., Pawson, S., Strahan, S. E., and Read, W.: Comparison of lower stratospheric tropical mean vertical velocities, J. Geophys. Res., 113, D24109, doi:10.1029/2008JD010221, 2008.
Solomon, S., Kiehl, J. T., Garcia, R. R., and Grose, W.: Tracer transport by the diabatic circulation deduced from satellite observations, J. Atmos. Sci., 43, 1603-1617, 1986.

Thibault, F., Menoux, V., LeDoucen, R., Rosenmann, L., Hartmann, J.-M., and Boulet, C.: Infrared collision-induced absorption by $\mathrm{O}_{2}$ near $6.4 \mu \mathrm{m}$ for atmospheric applications: measurements and empirical modeling, Appl. Optics, 36, 563-567, 1997.

Thompson, D. W. J. and Solomon, S.: Understanding recent stratospheric climate change, J. Climate, 22, 1934-1943, 2009.

Tuck, A. F., Baumgardner, D., Chan, K. R., Dye, J. E., Elkins, J. W., Hovde, S. J., Kelly, K. K., Loewenstein, M., Margitan, J. J., May, R. D., Podolske, J. R., Proffitt, M. H., Rosenlof, K. H., Smith, W. L., Webster, C. R., and Wilson, J. C.: The BrewerDobson circulation in the light of high altitude in situ aircraft observations, Q. J. Roy. Meteorol. Soc., 123, 1-69, 1997.

WMO (World Meteorological Organization): Scientific Assessment of Ozone Depletion: 2006, Global Ozone Research and Monitoring Project - Report No. 50, Geneva, Switzerland, 572 pp., 2007. 